\title{
Phase-of-firing information coding in laminar cortical architecture
}

\author{
Gleb Basalyga1*, Marcelo Montemurro², Thomas Wennekers ${ }^{1}$ \\ From Twentieth Annual Computational Neuroscience Meeting: CNS*2011 \\ Stockholm, Sweden. 23-28 July 2011
}

We applied recently developed information theory methods $[1,2]$ to the analysis of cortical responses in a largescale computational model of cat primary visual cortex [3]. These methods quantify the information conveyed by spikes and by local field potentials (LFPs) in a very general way, without ad hoc assumptions about precisely which stimulus features (orientation, direction, etc.) drive the neuronal response. The phase-of-firing information is the extra information obtained by labeling spikes with the value of the LFP phase [2]. In order to gain insight into the information-processing properties of laminar cortical microcircuits, we calculated the spike count information conveyed by firing rates and the phase-of-firing information conveyed by LFPs for each layer of primary visual cortex.

We found that there is substantially more information in the phase code compared with the spike rate alone for low LFP frequencies $(<30 \mathrm{~Hz})$. Figure 1 shows that the information gain for the phase code may reach $80 \%$ in Layer $2 / 3$, while in Layer 4 it reaches only $40 \%$, compared to the spike count code. These data support the hypothesis that the thalamo-cortical layers, which receive direct sensory input, may rely more on spikes to convey the information, while the cortico-cortical layers with strong recurrent connectivity may use the phase code and LFP signals for information coding.
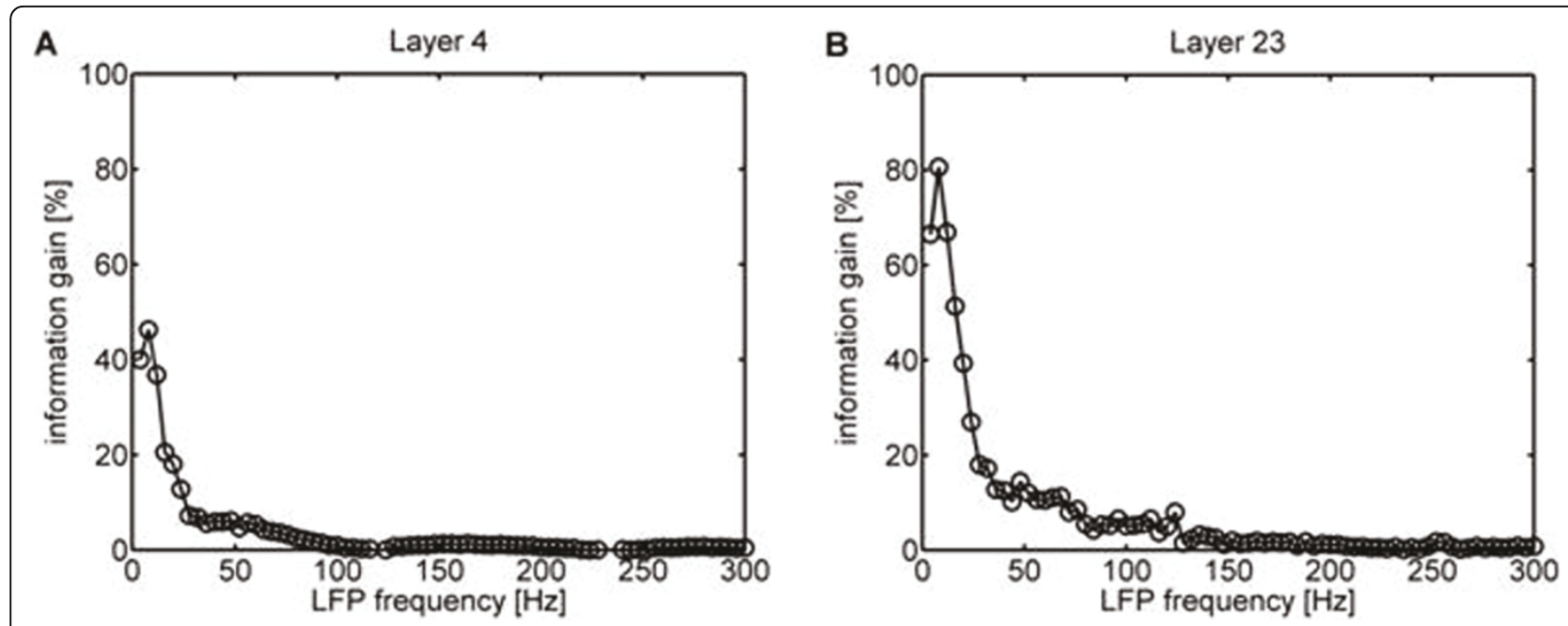

Figure 1 The phase-of-firing information as function of the considered LFP frequency (computed up to $300 \mathrm{~Hz}$ ). The circles denote the information gain by the phase-of-firing code compared to the spike count code for Layer 4 (A) and for Layer 2/3 (B).

\footnotetext{
* Correspondence: gleb.basalyga@plymouth.ac.uk

${ }^{1}$ Centre for Robotics and Neural Systems (CRNS), University of Plymouth, PL4 8AA, UK

Full list of author information is available at the end of the article
} 


\section{Acknowledgements}

This work was supported by EPSRC research grant (Ref. EP/C010841/1).

\section{Author details}

${ }^{1}$ Centre for Robotics and Neural Systems (CRNS), University of Plymouth, PL4

8AA, UK. ${ }^{2}$ Faculty of Life Sciences, University of Manchester, M13 9PT, UK.

Published: 18 July 2011

\section{References}

1. Montemurro MA, Panzeri S, Maravall M, Alenda A, Bale MR, Brambilla M, Petersen RS: Role of precise spike timing in coding of dynamic vibrissa stimuli in somatosensory thalamus. Journal of Neurophysiology 1871, 98(4):1882.

2. Montemurro MA, Rasch MJ, Murayama Y, Logothetis NK, Panzeri S: Phaseof-firing coding of natural visual stimuli in primary visual cortex. Current biology: CB 18(5):375-380.

3. Basalyga G, Wennekers T: Large-Scale Computational Model of Cat Primary Visual Cortex. BMC Neuroscience 10(Suppl 1):P358.

doi:10.1186/1471-2202-12-S1-P369

Cite this article as: Basalyga et al:. Phase-of-firing information coding in laminar cortical architecture. BMC Neuroscience 2011 12(Suppl 1):P369.

\section{Submit your next manuscript to BioMed Central} and take full advantage of:

- Convenient online submission

- Thorough peer review

- No space constraints or color figure charges

- Immediate publication on acceptance

- Inclusion in PubMed, CAS, Scopus and Google Scholar

- Research which is freely available for redistribution

Submit your manuscript at www.biomedcentral.com/submit 